\title{
EL DELITO EN EL ARCHIVO. DE ESCRIBANOS, FALSEADORES Y OTRAS GENTES DE MAL VIVIR EN LA CASTILLA DEL ANTIGUO RÉGIMEN*
}

por

\author{
Miguel A. EXTREMERA EXTREMERA \\ Universidad de Córdoba
}

RESUMEN: Tratamos aquí el tema de la imagen social que se crea de un grupo profesional en la Castilla del Antiguo Régimen, concretamente el de los escribanos públicos. Satirizados de manera recurrente en la literatura de la época, este trabajo se centra en el estudio de la tipología de todas las actividades delictivas que cometieron, atendiendo fundamentalmente a casos particulares. Con ello, desvelamos unas prácticas' a menudo encubiertas por el discurso oficial, y que tanta incidencia tuvieron en la imagen que se formó de todo el colectivo.

Palabras ClaVe: Escribanos públicos. Delito. Imagen social. Castilla. Edad Moderna.

ABSTRACT: This article addresses the social image of one particular professional group in Castile during the "ancien régime»: the public notaries, satirized repeatedly in the literature of the period. The article aims at a typology of illegal activities in which they engaged, paying attention to specific cases. In this way, we reveal a variety of practices frequently obscured by official discourse, but fundamental in their impact on the collective image of this group.

KEY WORDS: Notaries. Crime. Social image. Castile. Early Modern Period.

* Este trabajo, se inscribe en el marco del Proyecto de Investigación Cambio y continuidad. Las transformaciones sociales en las oligarquías municipales andaluzas (ss. XV-XVIII), BHA2003-09505C03-01, financiado por el Ministerio de Ciencia y Tecnología.

Hispania, LXV/2, núm. 220 (2005) 465-484 


\section{INTRODUCCIÓN. El DELITO Y LA FORMACIÓN DE LA IDENTIDAD DE UN COLECTIVO SOCIAL-PROFESIONAL EN EL ANTIGUO RÉGIMEN.}

En una fecha algo tardía que se sale de los límites cronológicos convencionalmente asignados a la Edad Moderna, concretamente el año 1837, un escribano de Fuentes de León elevó un memorial al Congreso Nacional que en ese momento discutía sobre los requisitos que se debían cumplir para ser elector, en relación a los intereses y prioridades de aquella nueva sociedad burguesa; el citado escribano, pedía en su memorial que se incluyese a los escribanos en tal categoría, con estas significativas palabras: «No diré que en esta clase [la de escribano] deje de haber algunos individuos que no merezcan contarse en su número. ¿Pero en cuál no los hay? ¿Y porque alguno sea indigno de ejercer aquel derecho se ha de condenar a todos? Hay escribanos malos, sí señor, pero los bay buenos buenísimos, y los hay que a ellos se debe la prosperidad de innumerables familias, y de aquí un beneficio conocido al Estado» ${ }^{1}$.

De su exposición se desprende la vigencia de un prejuicio, el prejuicio de identificar al escribano con ciertas malas artes, una idea fraguada durante siglos y que no se erradicaría en España hasta bien entrada la contemporaneidad. ¿A qué se debió ese prejuicio? Precisamente, a intentar desentrañar esta pregunta están destinadas las siguientes páginas.

Lo primero que llama la atención, es que es éste un tema que ha sido muy poco abordado por la historia social de la administración, en su conjunto. Para Castilla, y aunque disponemos de bastante información en fuentes judiciales - pleitos en Chancillerías, que utilizo aquí profusamente ${ }^{2}$ - municipales - actas capitulares, juicios de residencia ${ }^{3}$, etc.- literarias - referencias en autores como Quevedo, o Cervantes, por citar sólo dos ejemplos muy conocidos-, e incluso las propias fuentes notariales, no se ha tratado el tema, ni a nivel general ni al nivel particular de los diferentes cuadros del funcionariado. Prácticamente todos los trabajos que estudian algún aspecto de la administración en el Antiguo Régimen, a pesar de las noticias y referencias aisladas que hacen a cierto tipo de

1 Álvarez-Coca González, M. J.: «La figura del escribano», Boletín Anabad, XXXVII (1987), $n^{\circ} 4$, p. 563. La cursiva es mía.

2 Según Arribas Arranz, el Registro General del Sello, en Simancas, cuenta con numerosa información para el siglo XV. Habría que comprobar lo referentes a los siglos de la modernidad, en ARRIBAS ARRANZ, F.: «Los escribanos públicos en Castilla durante el siglo XV», en AAVV., Centenario de la Ley del Notariado, Sección Primera, Estudios Históricos, vol. I, Madrid, 1964, pp. 167-260.

3 Fuentes municipales como los juicios de residencia. Gracias a uno realizado en el concejo madrileño, en 1565, sabemos que los escribanos fueron acusados de falsificación de documentos, de excederse en sus atribuciones y de confabularse con procuradores y letrados en GUERRERO MAYLLO, A.: El Gobierno Municipal de Madrid (1560-1606), Madrid, 1993, p. 61. Sobre la importancia del juicio de residencia como fuente para este aspecto y otros de la historia social y urbana de los municipios, vid. BERNARDO ARES, J. M. de: «Los juicios de residencia como fuente para la historia urbana", en Bernardo ARES, J. M. de: El Poder Municipal y la Organización Politica de la Sociedad, Córdoba, 1998, pp. 67-100.

Hispania, LXV/2, núm. 220 (2005) 465-484 
irregularidades cometidas por aquellos profesionales, no le han dado el tratamiento monográfico que, a mi juicio, merece.

Y si este panorama no es muy halagador, aún menos resulta para el caso concreto de los escribanos públicos. Si bien es verdad que el asunto en cuestión ha sido tratado por autores como Martínez Gijón, desde una perspectiva más institucional, o María Jesús Álvarez-Coca González, que hace más hincapié en lo social, los datos reales aportados son mínimos, como ocurre con otros trabajos que aluden - $y$, en definitiva, eluden- al tema ${ }^{4}$. Una grata excepción la constituye el reciénte y muy sugerente trabajo de Enrique Villalba sobre los escribanos de la Corte en el Siglo de Oro, un islote en medio de todo un vacío historiográfico ${ }^{5}$. Y tampoco la historiografía europea se han pronuciado mucho sobre el tema, causando cierta sorpresa el silencio de países como Francia e Italia ${ }^{6}$.

Por tanto, poco se ha escrito sobre este otro aspecto del notariado en el Antiguo Régimen, y ello, como reitero, a pesar de lo recurrente de esta cuestión en fuentes históricas de todo tipo.

Es esto mismo, la continua presencia del tema en las fuentes, lo que habla de la magnitud del proceso. Sin embargo, hay quien, frente a las críticas recibidas por los escribanos del Antiguo Régimen, ha roto una lanza a favor del colectivo, de su profesionalidad y buen hacer ${ }^{7}$. Es verdad que fueron muy numerosas las críticas recibidas por los escribanos, quizás proporcionalmente desmedidas frente

4 Martínez Gijón, J.: «Estudios sobre el oficio de escribano en Castilla durante la Edad Moderna», en AAVV., Centenario de la Ley del Notariado, Sección Primera, Estudios Históricos, Vol. I, Madrid, 1964, pp. 328-336. ÁlvareZ-CoCA GonZÁleZ, M. J.: «La figura del escribano», op. cit., pp. 555-564. Esos otros trabajos que menciono serían, por citar sólo algunos, los siguientes: GoNZÁlEZ DE AMEZÚA, A., "Apuntes sobre la vida escribanil en los siglos XVI al XVIII», en Opúsculos bistórico-literarios, tomo III, Madrid, 1953, pp. 279-307; y sobre escribanos de la chancillería acusados de cometer irregularidades, RuIz RODRíGUEZ, A. A.: La Real Chancillería de Granada en el siglo XVI, Granada, 1987, pp. 183-184. Por mi parte, ya hice alguna referencia a esta cuestión, en EXTREMERA EXTREMERA, M. A.: «Los escribanos de Castilla en la Edad Moderna. Nuevas líneas de investigación», Chronica Nova, 28 (2001), pp. 178-181. Fuera del territorio de Castilla, y concretamente para escribanos públicos de la Baja Edad Media, hay que destacar el trabajo de FerRER 1 MaLlol, M. T.: «Irregularitats i falsificaciones notarials», en Actes del I Congrès d'Historia del Notariat Catalá, Barcelona, 1994, 463-478.

5 Villalba, E.: «Sospechosos en la verdad de lo que pasa ante ellos. Los escribanos de la Corte en el Siglo de Oro: sus impericias, errores y vicios», Litterae, 2(2002), pp. 121-149.

6 Una interesante excepción allende nuestras fronteras, el trabajo de PETITJEAN, M., «Remarques sur la délinquance professionnelle des notaires dans l'ancien droit français», en GARNOT, B. (dir.), Juges, notaires et policiers délinquants, XIVe-XXe siècles, Dijon, 1997, pp. 113-128.

7 «Hasta ahora sólo se han tenido en cuenta, una y otra vez, las quejas contra ellos y los defectos que, en el ejercicio de su profesión, se señalaban cuando, muchas veces, se trata sólo de casos aislados o de pequeñeces (...) al gran número de notarios incapaces, contra los que se ha protestado con razón, podía oponerse un número, por lo menos, casi tan grande de colegas capaces y estimados a los que nunca se cita ni se tiene en cuenta en los estudios generales sobre el notariado», SCHMIDTTноме́, W: «Contribución al estudio de la historia del notariado en Alemania», en Centenario de la Ley del Notariado, Sección Primera, Estudios Históricos, vol. II, Madrid, 1965, p. 461. 
a los argumentos positivos que defendían al colectivo. Pero, de la misma forma que no pueden negarse las virtudes y honorabilidad de la profesión, tampoco puede desdeñarse una crítica que es fiel reflejo de una situación vivida y, en muchos casos, también padecida.

Dedieu, con gran acierto, ha dicho lo siguiente al respecto: «el nepotismo, el enriquecimiento personal, son fenómenos masivos que el más ciego o el más benévolo de los investigadores no puede ignorar. Tales fenómenos se califican, directamente $o$ indirectamente, como infracciones a una norma, a un estado ideal de cosas en el que no tienen que existir, sin ver que son la base misma sobre la que descansa el sistema y que tenían entonces un grado de legitimidad que han perdido en nuestros tiempos» ${ }^{8}$.

Aquí reside uno de los puntos clave para comprender el fenómeno del delito en la administración del Antiguo Régimen, el debate sobre la excepción y la norma, qué puede entenderse por una y otra en aquellos siglos; por esta cuestión que considero nuclear para entender la sociedad de la época, se han interesado autores como Foucault o Carlo Ginzburg 9 . Si entendemos, con estos últimos, que la frecuencia de los delitos fue en muchas ocasiones la norma más que la excepción en la sociedad del Antiguo Régimen, una sociedad que a menudo utilizó el delito para expresar sus conductas, el fenómeno deja de ser un llamativo señuelo fácilmente tratable para convertirse en un asunto que merece ser analizado, es más, diseccionado en sus múltiples facetas, para comprender algo más de los hombres y mujeres que vivieron aquella realidad, aquella «verdad eterna» que significó su momento histórico.

Prácticamente hasta hoy, la historia social de la administración en la España Moderna, y aunque parezca una contradicción, ha tenido muy poco de «social» ${ }^{10}$; siempre han sido trabajos institucionales basados en la legalidad vigente $o$, lo que es lo mismo, en el discurso del poder de la época, por emplear una terminología foucaultiana, que no es sino un marco ideal poco respetado en las prácticas, a juzgar por las documentos que han llegado hasta nosotros. ¿Qué o quién hizo más por dotar de identidad al colectivo, el discurso oficial, ese marco teórico fundamentado en todas las disposiciones y ordenanzas referentes a los escribanos, o el imaginario social que resaltó las prácticas ilegales, y que inunda toda nuestra literatura del Siglo de Oro?

La mala imagen que se tiene de ellos entre la sociedad de la época, bien reflejada como digo en la literatura del Siglo de $\mathrm{Oro}^{11}$, quizás no se deba tanto a

\footnotetext{
8 DEDIEU, J.-P.: «Procesos y redes. La historia de las instituciones administrativas de la época moderna, hoy", en CASTELlANO, J. L; Dedieu, J. P.; , LÓPEZ-CoRdóN, M. V.(eds.): La pluma, la mitra y la espada. Estudios de Historia Institucional en la Edad Moderna, Madrid, 2000, p. 16. La cursiva es mía.

9 Serna, J.; PONS, A.: Cómo se escribe la Microbistoria. Ensayo sobre Carlo Ginzburg, Madrid, 2000, pp. 99-100.

10 A pesar del ya lejano llamamiento que hiciera Molas RiBalta, P. et alii: Historia Social de la Administración Española. Estudios sobre los siglos.XVII y XVIII, Barcelona, 1980.

11 vid. VIllalba, E.: op. cit., pp. 134-136.

Hispania, LXV/2, núm: 220 (2005) 465-484
} 
que delinquen - todo el que puede, lo hace-, sino a que lo hacen teniendo una autoridad que les ha sido otorgada por el discurso del poder público, algo que, no escapará a nadie, también tienen en común con otros colectivos de la administración. Lo singular y realmente interesante aquí, es notar que sus mecánicas persuasivas resultan poco creíbles y carecen de eficacia, sencillamente, porque son desveladas ${ }^{12}$; la gran mayoría procede de una baja extracción social, el pueblo conoce sus orígenes, su autoridad no se ampara, como es el caso de la nobleza, en el recurso de una antigüedad remota, aunque ésta fuera casi siempre fingida. Es fácil minar esa «reciente» autoridad mediante la crítica a sus prácticas delictivas.

Deberíamos plantearnos como hipótesis de trabajo básica la de que los escribanos no son, per se, un colectivo socio-profesional corporativizado y perfectamente homogéneo: es el imaginario social el que les otorga cierta identidad colectiva. En definitiva, y como ya señalara Pierre Bourdieu, «la representación que los individuos y los grupos revelan a través de sus prácticas y sus propiedades forma parte integrante de su realidad social» ${ }^{13}$. En otras palabras, el imaginario social que se crea en relación a los escribanos públicos, derivado de sus prácticas, las delictivas y las que no lo son, acaba afectando a la identidad misma del colectivo; la representación se apropia de esa realidad social y le da un particular sentido.

Esto puede verse más claramente tomando una perspectiva historiográfica sobre la historia del notariado. En la historia tradicional, el notariado como institución se ha mostrado insuficiente para hablar de la supuesta identidad del colectivo. $\mathrm{Si}$ bien es verdad que cofradías y colegios de escribanos pudieron hacer de posibles configuradores de identidad, esto se limitaría aquí sólo a los escribanos numerarios de una ciudad, los que ejercen un oficio de escribano público del número, obviando al resto, una gran masa de población escribanil flotante. Por tanto, los escribanos públicos del número, los únicos que podían formar parte de cofradías y colegios de escribanos, serían tan sólo la punta del iceberg de toda una pléyade de escribanos particulares, escribientes a sueldo y auxiliares varios. Resulta absurdo pensar que el imaginario social se quedara sólo en aquellos escribanos que tenía una plaza numeraria; de hecho, podrían observar mejor y estarían más cercanos de todas otras aquellas situaciones que poco se asemejaban a esa otra figura en ocasiones tan inaccesible como la del escribano público numerario en su despacho.

También la historia social se ha mostrado muy limitada al respecto, dado la heterogeneidad de este "grupo" profesional, como se ha podido constatar por recientes investigaciones basadas en fuentes como los protocolos notariales, tan poco explotadas aún por lo que se refiere al notariado ${ }^{14}$. Cada vez hay más evi-

12 Es la reflexión de Roger Chartier, a propósito de la obra de Louis Marin, en CHARTIER, R.: Entre poder y placer. Cultura escrita y literatura en la Edad Moderna, Madrid, 2000, pp. 80-81.

13 Bourdieu, P.: La distinción, Madrid, 1998, pp. 563-564.

14 Vid. Herzog, T.: Mediación, arcbivos y ejercicio. Los escribanos de Quito (siglo XVII), Francfort, 1996. 
dencias de que en el Antiguo Régimen, la consideración social no respondía necesariamente al oficio que se desempeñaba. Por tanto, sería muy útil profundizar un poco más y reducir la escala de trabajo: por una parte, habría que adentrarse en el mundo de la familia, porque, entonces, uno no era tanto quién era sino de quién era, $\mathrm{y}$, por supuesto, atender a la historia factual, la de los hechos concretos, la de las discontinuidades ${ }^{15}$.

Sobre lo primero, ya he escrito algunas breves páginas con un mero carácter aproximativo ${ }^{16}$. Respecto a lo segundo, y desde una perspectiva atenta al incumplimiento de la legalidad por parte de los escribanos públicos, es sobre lo que centraré el presente trabajo.

\section{DELINQUIR EN EL OFICIO NOTARIAL.}

A menudo se ha dicho que la mala imagen que la literatura de la época nos da de la figura del escribano, se debe especialmente a sus actuaciones judiciales más que a las puramente escriturales o notariales ${ }^{17}$. En parte, fue así, pero las fuentes documentales completan este panorama con los actos delictivos cometidos en el desempeño de su ejercicio como notarios públicos. Y no hará falta decir que la tipología de los delitos en los oficios notariales, fue de lo más singular y variado. Desde falsificar documentos y firmas, o la ocultación malintencionada de registros, pasando por el cobro de derechos excesivos y la aquiescencia en presentar testigos falsos, disponemos de todo un elenco de ejemplos del tipo de delito que nos interesa en este trabajo, el del papel y la tinta ${ }^{18}$.

Empecemos por el primero que se acaba de citar. La falsificación documental era un delito tipificado en el Antiguo Régimen como grave, y más aún si el que lo cometía era una persona investida de fe pública, como un escribano o notario. Las Partidas contemplaban incluso la pena de amputación de un miembro - la mano con la que se cometía el delito-, aunque esta medida tan rotunda desaparecerá a comienzos de la modernidad, cambiándose por una sanción económica, la privación del oficio, el destierro y, a veces, presidio ${ }^{19}$.

15 FoucaulT, M.: El orden del discurso, Barcelona, 2002, p. 56.

16 Extremera Extremera, M. A.: «Los escribanos públicos de Córdoba en la Edad Moderna. Una aproximación sociológica», Axerquía, 19(2002), pp. 97-109.

17 ANGULO, A.: «El escribano público: una aproximación a su figura y a la de las escribanías vitorianas (1700-1750)", en PORRES, R (dir.): Aproximación metodológica a los Protocolos Notariales de Álava (Edad Moderna), Vitoria, 1996, p. 30, nota 14. También sostuvo este parecer González de Amezúa, para quien «en cambio, las críticas y diatribas contra estos mismos escribanos de número en su ministerio propiamente notarial son más bien raras», en GONZÁLEZ DE AMEZÚA, A.: op. cit., pp. 284-285.

18 Una completa tipología delictiva de los escribanos del crimen, ejemplificada en la visita realizada en 1608 al escribano Juan de Piña, en VILlalbA, E., op. cit., pp. 142-144.

19 Alejandre García, J. A.: «Estudio histórico del delito de falsedad documental», Anuario de Historia del Derecho Español, XLII(1972), pp. 175-178.

Hispania, LXV/2, núm. 220 (2005) 465-484 
El hecho de falsear determinados documentos era debido, en opinión de muchos, al bajo nivel de vida y a la precaria situación económica en que se encontraban a menudo los escribanos públicos. Según el inglés Townsend, era la pobreza de los escribanos, junto a su falta de principios, la causa de que se prestasen a alterar registros documentales ${ }^{20}$.

Para evitar falsificaciones, durante el reinado de Felipe IV se estableció el uso del papel sellado; o ése era al menos el argumento oficial, porque esta medida tenía unos claros fines recaudatorios si atendemos al contexto en el que se aprobó ${ }^{21}$. Sin embargo, poco después de instaurarse, muchos de los escribanos no lo respetaron, como fue el caso de Andrés del Castillo León. Imputado con varios cargos de falsificación de documentos y firmas a mediados del siglo XVII, también se le acusa de no respetar la medida referente al papel sellado ${ }^{22}$.

La falsificación de documentos, y muy especialmente, la alteración, suplantación y copia de firmas, tuvo que ser bastante común en la época; sólo así se explica que se soliciten muy a menudo los servicios de peritos calígrafos que pudiesen cotejar documentos y firmas para comprobar la veracidad de los mismos. Para ello, estos prestaban atención tanto al trazado de la escritura como al tipo de tinta utilizado, entre otros factores ${ }^{23}$.

Sin embargo, bastantes de estas falsificaciones no siempre tuvieron la buena factura que las liberara de toda sospecha y las hiciera pasar por auténticas. En época de los Reyes Católicos, en un contexto de rivalidad por hacerse con la escribanía del concejo de Cuenca, apareció una falsificación bastante burda de un documento que teóricamente correspondía al año 1436: «el acta no está signada, ni señalada de escribano público, tal como lo están las demás contenidas en el registro; la caligrafía difiere de aquella en la que está realizado el resto del registro; la hoja no está encuadernada en el tomo del registro, sino cosida; detrás de la hoja en cuestión han sido arrancadas otras [...], como se trataba de la última hoja de ese toma del registro, para disimular habían cosido detrás suyo un cuadernillo, que queda situado en una colocación incorrecta, por los asuntos que en él se tratan y las fechas a las que responde». El autor, según el informe judicial, el escribano del número de Cuenca Alfonso González de Huerta, que ya

20 TOWNSEND, J.: Viaje por España en la época de Carlos III, Madrid, 1988, p. 345.

21 La disposición es de 15 de diciembre de 1636 , cuando eran verdaderamente problemáticas las necesidades financieras de la máquina estatal, en ARCO MOYA, op. cit., p. 845.

22 Se trata del cargo número 8 de los que se le acusa: «en contravención de lo dispuesto en las pragmáticas S. M. del papel sellado, teniendo obligación como por ella se manda a notar en los registros las sacas de los escribanos que de ellos da, y poner en la dicha anotación el papel sellado en que la saca, no lo hizo sino sólo puso que había dado traslado de algunas escrituras sin decir en qué papel», en Archivo de la Real Chancillería de Granada (en adelante, ARChG), Legajo 105, pieza 7.

23 Sobre la tinta, CÁrCel OrTí, M. M.; TrenCHS OdenA, J.: «La tinta y su composición. Cuatro recetas valencianas (siglos XV-XVII)", Revista de Arcbivos, Biblioteca y Museos, LXXXII(1979), $\mathrm{n}^{\circ}$ 3, pp. 415-426. El aprendizaje o perfeccionamiento en el arte de escribir, en EGIDO, A., «Los manuales de escribientes desde el Siglo de Oro. Apuntes para la teoría de la escritura», Bulletin Hispanique, 97(1995), $\mathrm{n}^{\circ} 1$, pp. 67-94. 
tenía una mala reputación y un currículo bastante completo en lo referente a falsear documentos ${ }^{24}$.

Resulta obvio que muchos de los escribanos que falsearon documentos, no eran nuevos en la actividad delictiva. Ya en el Setecientos, en uno de los protocolos del escribano público y del ayuntamiento de la villa de La Zarza, en el partido de la ciudad de Mérida, se halló un documento con una firma falsificada de D. Pedro Campos, caballero de Santiago y vecino de dicha villa. El escribano en cuestión no sólo era responsable de esto, sino que ya se hallaba en la cárcel «por otros excesos en esta dicha ciudad y sus arrabales» 25 .

Y la falta de escrúpulos y osadía llegaba en ocasiones tan lejos, que no les temblaba el pulso al falsificar las firmas de las más altas instancias de la administración local. En 1792, el corregidor de la villa de Andújar denuncia que su firma ha sido falsificada en los cuadernos de asientos por el escribano del cabildo de la misma, Pedro Valero, con lo que el dicho escribano se embolsó «la parte correspondiente a S. M. en las penas de cámara como asimismo la respectiva del juez la del denunciador y también la que toca a propios» ${ }^{26}$.

Tampoco el alterar con pericia un documento era la única forma de delinquir. La simple ocultación de un registro notarial o de cualquier otro tipo en un momento determinado, podía traer también funestas consecuencias para el perjudicado. Una práctica ésta, alentada y auspiciada, en ocasiones, por los señores de las villas, en connivencia con sus escribanos ${ }^{27}$. Pero, debido a la ambigüedad que sin duda existe entre la ocultación voluntaria de documentos, por un lado, y la pérdida de los mismos, teóricamente involuntaria, por otro, me referiré a este punto más adelante, al hablar de la negligencia como uno de los «privilegios» de la información de que gozaban los escribanos públicos.

Cambiando de asunto, son varias las causas que pueden enumerarse del cobro de derechos excesivos por parte de los escribanos a la hora de realizar su trabajo ${ }^{28}$. En primer lugar, el número de escribanos era relativamente grande, especialmente en los núcleos urbanos, por lo que tenían que cobrar más si querían hacer rentable el oficio, un oficio, no lo olvidemos, cuya compra suponía ya de entrada un importante desembolso monetario ${ }^{29}$. A esto habría que sumarle uno de los argu-

24 RÁBADE ObRadó, M. P.: «Las escribanías como conflicto entre poder regio y poder concejil en la Castilla del siglo XV: El caso de Cuenca»; Anuario de Estudios Medievales, 21(1991), p. 271.

25 ARChG, Legajo 4435, pieza 11.

26 ARChG, Legajo 4400, pieza 75.

27 Vid. GARCíA HeRNÁN, D.: «El gobierno municipal en las villas de señorío. Siglo XVI», en BERNARDO ARES, J. M. de; MARTíneZ RUIZ, E. (eds.), El municipio en la España Moderna, pp. 191-215.

28 Son muchos autores los que están de acuerdo en que el cobro de aranceles era el pilar económico básico del sustento de los escribanos: «el rendimiento de la profesión lo constituyen propiamente los derechos que se perciben por las escrituras", según GUERRA GUERRA, A., "Escribanos badajocenses del siglo XVI», Revista de Estudios Extremeños, 33 (1) (1977), p. 13.

29 Lázaro Pozas asegura que era el principal motivo aducido por los capitulares en los razonamientos de petición al poder central para que éste ordenase la reducción de las escribanías del número de la ciudad, porque eran tantas y tantos los escribanos que tenían que repartirse los negocios, que transgre- 
mentos más recurrentes en la defensa de los escribanos encausados por el cobro de derechos excesivos: el desconocimiento, la existencia de distintos aranceles según los lugares y la confusión que se seguía de todo ello.

Fuere como fuere, hay algunos casos que llaman especialmente la atención. Gregorio de Valenzuela, escribano público del número de la ciudad de Alhama, por los testimonios necesarios para la posesión de una capellanía, recogidos en tan sólo nueve hojas, llevó nada más y nada menos que 1.050 reales $^{30}$. A pesar de cobrar tan considerables honorarios, tenía escasos conocimientos paleográficos porque no sabía leer escrituras antiguas, aunque en este punto no se diferenciaba mucho de sus colegas ${ }^{31}$. Otro escribano, éste de Antequera, había percibido en exceso de sus derechos más de 900 reales. Si es verdad que, como aducen algunos de los escribanos acusados de este tipo de delito, su conducta se debe a la diferencia de aranceles según los sitios, o simplemente a su desconocimiento ${ }^{32}$, unas cantidades tan exorbitantes como las mencionadas para sólo unos cuantos folios despejan cualquier tipo de duda.

Otros, ni siquiera aprovechaban la excusa de los aranceles para hacer dinero fraudulento. Por ejemplo, algunos escribanos de cabildo lo cogían directamente de las arcas municipales si tenían la ocasión. A principios del siglo XVIII, desempeñó este cargo en la ciudad de Córdoba don Roque Dionisio de Carrasquilla, perteneciente a una importante familia de la mesocracia urbana. Por un documento bastante revelador, un memorial que otorgó poco después de su testamento, sabemos que, como él mismo confiesa, había "tomado" de las arcas del común 8.800 reales, cifra nada desdeñable. Expuso que actuó de esa forma porque se le debía el salario de tres años ${ }^{33}$.

Un aspecto más, aunque no de forma directa y al que hay que atender con especial cautela, nos permite aproximarnos a algunas otras posibles formas de delito encubierto. En los protocolos notariales, concretamente en los testamentos de algunos de estos profesionales, se suele destinar una cantidad de dinero a

dían las leyes cobrando excesivos derechos puesto que la abundante competencia aminoraba sus ingresos, en POZAS POVEDA, L.: «Aproximación al estudio del oficio de escribano público del número de la ciudad de Córdoba en la primera mitad del siglo XVIII", Axerquía. Revista de Estudios Cordobeses, 14 (1985), p. 112; vid. también, ÁlvAREZ-COCA GONZÁleZ, M. J.: op. cit., pp. 561-562.

30 ARChG, Legajo 2179, pieza 2, año 1777.

31 GALENDE DíAZ, J. C:: "Historia de la paleografía en España. Los revisores de letras antiguas", Cuadernos de Investigación Histórica, 16(1995), p. 173.

32 El caso del escribano de Antequera, en ARChG, Legajo 4319, pieza 17. Este escribano se defendió aduciendo que los derechos llevados, aunque no eran conformes al arancel, «no son excesivos en esta plaza, atendiendo a la ninguna comparación que estos gastos tienen con los de otro cualquier pueblo, a que no hay arancel fijo que por el número ni demás dependientes de justicia se siga, y al estilo seguido que invariablemente por todos se observa, y otras razones». Es también el argumento de la defensa de los escribanos de Lorca, acusados en 1776 de esta misma práctica, en ARChG, Legajo 4430, pieza 30.

33 Archivo Histórico Provincial de Córdoba, Of. 16, leg. 150, fols. 255/261v., 9 mayo 1714, escribano Francisco Antonio Ruiz de Morales. 
personas de las que nada se dice; el motivo, según se expone, sobre algo que el otorgante habló en privado con su confesor y, también en ocasiones, con su esposa. Esta práctica, que muy posiblemente encubra algún tipo de acto delictivo, suele ser bastante común entre mercaderes y negociantes varios, debido a una especie de remordimiento por haber cometido ciertas estafas con algunas personas durante el desempeño de su negocio. Que dicha práctica aparezca en el testamento de un escribano, resulta bastante significativo ${ }^{34}$.

Por último, un delito que también debió de ser muy común fue la presentación de testigos falsos. Por auto de 1 de junio de 1586, sabemos que un escribano público de la villa de La Rambla, compró a dos testigos para que testificasen a favor de una mujer castigada por amancebada; ella tenía que casarse con el que estaba amancebada, ellos dirían que su primer marido estaba muerto - la realidad es que llevaba ausente de su casa mucho tiempo-, y el dicho funcionario los recibiría como escribano ante la Justicia Real. Descubierto todo, la pena para el escribano fue el destierro y la suspensión del oficio por medio año, así como el pago de cuarenta ducados ${ }^{35}$.

Como vimos más arriba, el descubrimiento de las tretas y malas artes de un escribano en la Castilla del Antiguo Régimen solía terminar con una sanción económica, la suspensión del oficio y el destierro. Era el alto precio que, en ocasiones, debían pagar por detentar una situación tan privilegiada desde la que controlaban mucha información.

\section{LOS «PRIVILEGIOS» DE LA INFORMACIÓN: DESPOTISMO, FRAUDE, NEGLI- GENCIA Y ALGÚN QUE OTRO SUSTO.}

La información era algo muy cotizado en una sociedad como la del Antiguo Régimen. En este sentido, los escribanos tienen un primerísimo papel ${ }^{36}$. Más aún si cabe, en las pequeñas villas rurales, en donde la autoridad del escribano - en ocasiones, sólo hay uno de estos funcionarios - puede equipararse a la de otras figuras de este paisanaje rural como el alcalde mayor, el cura o el médico; como dijo hace ya bastante tiempo González de Amezúa, sus demasías en los lugares y pueblos pequeños los convertía en auténticos tiranos para la población ${ }^{37}$.

Es realmente muy poco lo que sabemos en la actualidad sobre los escribanos rurales, aunque una cosa parece estar bastante clara; los miembros de la

\footnotetext{
34 Entre los varios casos, uno como ejemplo: D. Pedro Martínez Valcárcel, escribano del número de Córdoba, perteneciente a otra importante familia de escribanos, declara en su testamento que debe restituir 200 pesos escudos a diferentes personas, sobre algo que ya había hablado con sus confesores y su mujer, en Archivo Histórico Provincial de Córdoba, Of. 16, leg. 150, fols. 174/177v., 30 julio 1714, escribano Francisco Antonio Ruiz de Morales y Rabago.

35 Gracia BoIX, R: Autos de Fe y Causas de la Inquisición de Córdoba, Córdoba, 1983, pp. 206-207.

36 Extremera EXtremera, M. A.: «La pluma y la vida. Escribanos, cultura escrita y sociedad en la España Moderna (siglos XVI-XVIII)", Litterae, 3-4 (2003-2004), pp. 187-206.

37 GONZÁlez De AMEZÚA, A.: op. cit., 283. 
propia familia y su círculo de amistades solían ser cómplices en los actos delictivos de los susodichos escribanos, especialmente si detentaban también algún cargo de responsabilidad pública.

Un escribano público de Écija, «uno de los peores de la península», según las fuentes judiciales, Agustín Ignacio Salgado, y su hermano, alguacil mayor, cometieron todo tipo de fechorías. De él se dice lo siguiente: «que este escribano acostumbraba la suposición de depósitos judiciales y llevarse a su poder los bienes embargados y desapareciéndolos y convirtiéndolos en su beneficio y utilidad». Como ejemplo, el citado escribano Salgado actuó en 1767 en una causa de hurto, por la que se embargaron diferentes bienes a los reos. Resultó que, tras una averiguación del paradero de dichos bienes, el escribano y su hermano, alguacil mayor, se llevaron de los depósitos judiciales dos cerdos y tres jumentos, entre otros bienes ${ }^{38}$.

Por otro lado, el escribano de cabildo de Huécija - en la actual provincia de Almería - llamado Compán, y su yerno, que era alcalde mayor, cometieron numerosos fraudes; gozaban de cierta inmunidad por la «autoridad y respeto» que despertaban. Según las fuentes, estuvieron durante bastante tiempo «actuando y despachando yerno y suegro, de que se han seguido graves perjuicios a los vecinos, y que al citado escribano le había simulado el alcalde mayor sus excesos [...] y últimamente, siempre que conoce que algún vecino puede descubrir los excesos a dicho escribano, procura suponerle causas bien a él o a alguno de su familia, y se vale de personas de su facción para ello» ${ }^{39}$.

Otro familiar, en cierta forma, también se les sumó. Se trataba de Blas Martínez, alcalde decano de la misma villa de Huécija y que estaba casado con una sobrina del escribano. Pero, como he dicho, no sólo quedaba todo en familia; las clientelas, el compadrazgo y las amistades también tenían su papel. $\mathrm{Al}$ anterior tándem, se sumaron asimismo los dos alcaldes pedáneos de la villa de Alhama de Almería. De esta forma, y simulando una práctica empleada por la media y alta nobleza castellana, crearon una facción cuya radio de acción se extendía más allá de los límites físicos de la villa. De hecho, sabemos que cuando no se podía recurrir a la familia, ahí estaban los poderosos de los lugares; el escribano de Alcalá la Real, Juan Antonio Serrano, también gozó durante tiempo de cierta impunidad para cometer todo tipo de fechorías "por el mucho poderío y manejo que tiene con los regidores ${ }^{40}$.

La llegada de las tropas napoleónicas y el convulso período que se vivió, fue una excelente oportunidad para que se practicaran desmanes varios. En 1813, unos cuantos vecinos de la villa de Almogía, en Málaga, denuncian los perjuicios que les había causado el escribano Antonio Vuélcanos durante la dominación francesa; entre otros, el estupro de una joven y el asesinato de varios hijos de los

38 ARChG, Legajo 4431, pieza 56.

39 ARChG, Legajo 4413, pieza 37.

40 ARChG, Legajo 4434, pieza 68. Respecto a su conducta inmoral, vid. infra. 
denunciantes, haciendo responsable de todo esto al citado escribano. Además, la villa solicitaba poder comprar la escribanía perteneciente al suegro de Antonio Vuélcanos, el también escribano Bernardo Moraga, «puesto que así el Moraga como el Buercanos han hecho desaparecer la paz de entre aquellos habitantes» ${ }^{41}$.

A este tipo de fraudes y actos delictivos, cometidos en pequeños núcleos rurales, habría que añadir la inveterada costumbre de muchos escribanos de incentivar los pleitos. Un sabroso texto del padre Isla, en su Fray Gerundio de Campazas (1758), nos ofrece algunos datos sobre el escribano de un pequeño pueblo: «Cuando entró en el pueblo, pues fue el primer escribano que entró en él, no había pleito ninguno, ni aún memoria de que le hubiese habido jamás desde su primera fundación; pero al año, y no cabal, de su residencia, ya todo el lugar se ardía en pleitos; y cuando murió, dejó pendientes treinta y seis, aunque no pasaba la población de doscientos vecinos. Encendía a unos, azuzaba a otros y los enzarzaba a todos» ${ }^{42}$.

También en Huelva, el escribano público y del cabildo, Juan Antonio Rivero, fue acusado de ser el causante de las discordias que habían surgido recientemente en muchos pueblos, debido a que era un «hombre vago, sin arraigo ni obligaciones, de genio inquieto" ${ }^{43}$.

Su autoridad, en ocasiones, también se manifiesta en contra del poder amparándose en el pueblo llano. Es el caso de un escribano perseguido por la oligarquía local y alabado por sus vecinos; aunque esa oligarquía la formen incluso, como se trata aquí, miembros de su misma familia. El escribano de la villa de Moclín, en Granada, Francisco Ruiz de Prado, en 1772, vio cómo dos primos hermanos, uno alcalde y otro alguacil mayor, le encausaban. Salieron a su defensa varios vecinos y labradores de la villa, que expusieron que el motivo era "porque sacaba la cara el escribano corrigiéndoles este exceso y reconviniéndoles no era razón sufriese el pobre común lo que ellos no querían pagar, le tomaron el interés y enemiga que tienen manifestado en el procedimiento y apremio al pago de dicha existencia [.... $\gg^{44}$. Sería interesante indagar en profundidad en el mundo rural, donde, en ocasiones, los escribanos se convierten en cabezas visibles del descontento campesino, ya sea contra los señores, ya sea contra los oligarcas de las villas y lugares.

Por otro lado, no debemos olvidar que a veces ese privilegio de la información se podía volver en contra de ellos mismos; así, están documentados intentos de agresión ${ }^{45}$, lo que nos demuestra de nuevo la importancia que tuvieron

41 ARChG, Legajo 4443, pieza 41.

42 PADRE IsL.A, Historia del famoso predicador Fray Gerundio de Campazas, Madrid, 1978, Tomo II, p. 656.

43 GonZÁlez CRUZ, D.: Escribanos y notarios en Huelva durante el Antiguo Régimen (1701-1800), Huelva, 1991, pp. 125-126.

44 ARChG, Legajo 4434, pieza 16, año 1772.

45 Respecto a los escribanos públicos de la Sala de alcaldes de Casa y Corte, Enrique Villalba señala cómo algunos fueron insultados e incluso agredidos físicamente, en VILLALBA, E.: op. cit., pp. 132-133.

Hispania, LXV/2, núm. 220 (2005) 465-484 
como individuos que pertenecían a un colectivo reconocido e identificado como tal por la sociedad.

El escribano público y del cabildo de Castro del Río, don Francisco de Varo Franco, se querelló en 1754 contra don Luis de Herrera, que se decía vecino de Córdoba. El motivo, el intento de agresión que sufrió el escribano al negarse a darle al acusado un recibo de los derechos que estaba debiendo por un pleito que seguía el segundo. Tras la negativa, al día siguiente se dirigió con un criado suyo, embozado, al despacho del escribano, y al volver a negarse éste, «echó mano a una terciado o sable que traía oculto y preparado para el lance, y al tiempo de arrancarlo para darme con él, le detuvo la acción asiéndole el brazo uno de dichos mis oficiales, que a no haberlo impedido por dicho medio me hubiera herido o dado muerte» ${ }^{46}$.

Otra cara poco amable de este privilegio de la información, está relacionado precisamente por la alteración o pérdida de la misma. Me refiero a los casos documentados de negligencia y dejación, algo que podríamos calificar como una especie de "delito pasivo». En ocasiones, pudo tratarse de negligencias involuntarias, por su poca preparación e incompetencia ${ }^{47}$; en otras, fueron conscientes de sus faltas y no tuvieron el más mínimo remordimiento ni voluntad de enmendar el error, negándose a testificar a favor de las víctimas. A este respecto, ¿podríamos hacer extensible a los escribanos la categoría de «instituciones memorizadoras» con la que Armando Petrucci ha designado a archivos y bibliotecas, como lugares donde se ha conservado la memoria escrita? ${ }^{48}$ Creo que sí, debido a su importante papel en la conservación, transmisión y, como también acabo de manifestar e inmediatamente veremos ejemplificado, en la pérdida de la memoria escrita.

Juan Álvarez, vecino de Ponferrada durante el reinado de los Reyes Católicos, «realizó unas escrituras ante un escribano venido de Astorga, y que apenas estuvo un año sirviendo el oficio en Ponferrada, para regresar después a su tierra de origen. Cuando el testigo, envuelto en un pleito, trató de obtener dichas escrituras, descubrió que las mismas se habían extraviado, razón por la que perdió el pleito" ${ }^{49}$. Bajo esto se encuentra latente un problema: el del enraizamiento del escribano. Siempre fue un sinónimo de garantía el hecho de que el escribano fuera de una conocida y antigua familia de la ciudad, de que formara parte de esas auténticas sagas de escribanos que pululaban por todas las ciuda-

46 ARChG, Legajo 2326, pieza 6. Según se recoge en el libro de Luján Muñoz sobre los escribanos de Guatemala, un escribano de concejo llevaba escolta; quizás, fuera a costa del propio concejo, cosa que no ocurre en el caso de los escribanos públicos, bastante vulnerables en este sentido, en LuJÁN MUÑoz, J., Los escribanos en las Indias Occidentales, México, 1982.

47 Extremera Extremera, M. A.: «Los escribanos de Castilla en la Edad Moderna. Nuevas líneas de investigación», op. cit., pp. 181-182.

48 Petrucci, A.: Alfabetismo, escritura, sociedad, Barcelona, 1999, p. 292.

49 RÁBADE OBRADÓ, M. P.: «Las lugartenencias de escribanías como conflicto: un ejemplo de la época de los Reyes Católicos», Espacio, Tiempo y Forma, Serie III, Historia Medieval, t. V, 1992, p. 223. 
des y villas castellanas del Antiguo Régimen, aquellas pocas familias ejemplares o paradigmáticas, referenciales, sin duda ${ }^{50}$.

Tiempo después, en 1622 , se presentó una querella contra el escribano de una villa de las Alpujarras por no haber entregado el traslado del proceso y los autos de un pleito a la parte perjudicada, un labrador que se encontraba preso y que, por la dilación del escribano, veía cómo su hacienda se estaba perdiendo sin poder cultivarse ${ }^{51}$. Aquí, la dejación es más que evidente.

Añadamos a esto un caso de negligencia. El escribano de la justicia Gabriel Bautista, fue azotado el jueves 21 de junio de 1629, según recoge Morales Padrón en Memorias de Sevilla, "por haber hecho información falsa de un homicidio, achacándoselo a quien no lo había cometido» ${ }^{52}$. Como vemos, las tretas de un escribano, consciente o inconscientemente, podían complicar mucho la vida a personas de todo punto inocentes.

Por último, cuando la dejación no sólo podía perjudicar a alguna persona en particular, sino a toda una comunidad; algo que ocurrió en los cabildos municipales en relación a su gestión y capacidad económica. Según un interesante trabajo de Leonor Zozaya, en el Madrid de Felipe II hubo cuantiosas pérdidas económicas por la despreocupación de los escribanos públicos en los asuntos de la villa ${ }^{53}$, pero esto excede ya los límites de este trabajo.

\section{UNAS VIDAS MUY POCO EJEMPLARES.}

La buena conducta era una cuestión fundamental para este colectivo; de hecho, uno de los requisitos para conseguir el título de escribano público era, precisamente, «ser de buenas costumbres». Este discurso oficial se correspondía con una realidad social cuya exigencia demandaba, precisamente, que estos profesionales fueron gente honrada y de probadas virtudes morales. Investidos de una fe pública que emanaba del mismísimo rey y les llegaba, de manera particular a cada uno de ellos, a través de un título real de escribano, la redacción y custodia de documentos tan vitales y valiosos para tantas y tan distintas familias no hicieron sino reafirmar su condición y su enorme responsabilidad social. Si un nivel y otro, el exigido por la institución y el exigido por la propia sociedad, tuvieron su innegable razón de ser y estuvieron plenamente justificados, esto no evitó que, una vez más, los hechos se alejaran de la teoría, que la excepción consiguiera burlar a la norma: una vez más, podemos afirmar junto a

\footnotetext{
so Vid. Extremera Extremera, M. A.: «Los escribanos públicos de Córdoba en la Edad Moderna...», op. cit., p. 105.

s1 ARChG, Legajo 2297, pieza 4.

52 Morales Padrón, F. (ed.): Memorias de Sevilla, (1600-1678), Córdoba, 1981, p. 64.

53 ZOZAYA, L., "Mermas de poder económico debido a la pérdida documental en los archivos de la Villa de Madrid en tiempos de Felipe II», en Aranda Pérez, F. J. (coord.), El mundo rural en la España Moderna, Cuenca, 2004, pp. 1295-1306.

Hispania, LXV/2, núm. 220 (2005) 465-484
} 
Michel de Certeau que «le fait, c'est la différence» ${ }^{54}$. Efectivamente, y como no podía ser de otra forma, la vida de muchos escribanos públicos no fue un dechado de virtudes.

El escribano del cabildo de Alcalá la Real, allá por el año 1760, don Juan Antonio Serrano, a pesar de llevar casado legítimamente más de diez años, estaba amancebado con una mujer soltera con la que ya había tenido cuatro o cinco hijos; evidentemente, la justicia eclesiástica tenía aquí competencias, y Serrano fue procesado, pero su caudal y, lo que es más importante, su relación con los poderosos del lugar, como dije antes, evitaron que saliese del trance sin la menor pena ni padecer la prisión, como era lo que le correspondía. Según las fuentes, prosiguió teniendo a dicha mujer soltera e hijos manteniéndolos de lo necesario 55 .

A fines de esa misma centuria, el escribano Carlos Martínez Talavera, escribano oficial en la Chancillería de Granada, fue acusado de ciertos excesos y de conducta inmoral. Según el testimonio de su mujer, se ausentaba a menudo de su casa y tenía trato ilícito con una tal María Milagros, «una con quien se presenta en todas las funciones de novillos»; además, el trato vejatorio dado a su mujer y a su suegra así como amenazas tales como «que la casa merecía que le pegasen fuego", eran continuos. A todo ello, había que sumar que ya había estado preso por irregularidades en el desempeño de su oficio, concretamente por retener en su poder varias causas y papeles ${ }^{56}$.

$\mathrm{Al}$ margen de estos casos de conducta inmoral, el peor ejemplo para la profesión lo daban aquellos que no es que tan sólo fueran sorprendidos en algún desliz, sino que habían establecido por regla en su profesión delinquir de las más variadas y tergiversadas formas. Supondrían algo así como auténticos ejemplos vivientes del delito. Pues bien, me centraré concretamente en tres de estos escribanos: Antonio Compán, Andrés del Castillo y Agustín Ignacio Salgado, de los cuales ya he mencionado muy puntualmente algunos de los muchos delitos que engrosaron su particular currículo delictivo. En esta ocasión, por tanto, reduzco la escala de análisis para observarlos más en detalle.

En primer lugar, el caso de Antonio Compán, escribano del cabildo de la villa de Huécija, en la actual provincia de Almería ${ }^{57}$. Antes de 1773, cuando se le forma esta causa, ya había sido desterrado por cometer varios excesos, pero consiguió que se le levantara el destierro conmutándolo por una pena pecuniaria.

Ahora, para empezar, se le acusa de conducta inmoral. Frecuenta las tabernas o estancos de vino, y estando embriagado se va a sus oficinas, donde, en ese estado y junto a otras personas de su facción, habla de forma deshonesta e indecente, dando mal ejemplo a los niños de corta edad.

Por otra parte, es el abastecedor tanto del vino - ese vino que bebía en cantidad - como de la carne; el vino lo vende por mano de su cuñada, con lo

54 Certeau, M. de: L'écriture de l'bistoire, París, 2002, p. 112.

is ARChG, Legajo 4434, pieza 68.

ARChG, Legajo 4443, pieza 60.

ARChG, Legajo 4413, pieza 37. 
que se vende más caro en la villa que en los lugares inmediatos; respecto a la carne, las reses de la manada del escribano andan por las vegas de riego, a pesar de la prohibición existente sobre este particular.

Muy destacable es el cuarto cargo que se le impúta, y que nos da las pistas de su impunidad y del «gran miedo y temor que todos le tienen»: con la ayuda de su yerno, que es ni más ni menos que el alcalde mayor de la villa, consigue que las asuntos tratados en el cabildo salgan a los fines que más le convienen a él. El grado de connivencia entre ambos llega a tal extremo, que incluso viven en las mismas casas ${ }^{58}$.

A todo esto, añadir que ponen cuantiosas multas a vecinos que, de acuerdo con la costumbre, entran sus ganados para que pasten sus rastrojos una vez que se han levantado los frutos, así como que en la feria que anualmente se celebra en la villa por S. Agustín, ambos, escribano y alcalde mayor, han estafado a los feriantes sacándole con título de agasajo varias cantidades.

Por supuesto, cuando el escribano sospechaba que algún vecino pudiese descubrir los excesos cometidos, procuraba suponerle causas bien a él o a alguno de su familia. De esta forma, pusieron a un vecino, Indalecio Ferrer, «en una rigurosa y estrecha prisión, cargándole de dos pares de grillos, esparciendo voces dicho escribano que hasta que perdiese a mi parte y sus hermanos no había de parar».

El segundo caso que traigo a colación, no es menos significativo. Me refiero al de Andrés del Castillo León, escribano público de Córdoba a mediados del siglo XVII ${ }^{59}$. Según se dice, por sus malas artes, había mucha gente en la ciudad temerosa de que no falsificase sus firmas para cometer fraudes; ya estuvo preso por algunos de estos fraudes, como la querella que contra él interpuso el convento de S. Pablo, en la que se le imputó haber supuesto una escritura falsa en su favor y haberla introducido, subrepticiamente, en los registros y notas del escribano Roque Ramírez de León. Asimismo, por la querella que contra el dicho Castillo presentó $\mathrm{D}^{\mathrm{a}}$ Leonor de Acevedo, perteneciente a la nobleza local, sobre haber supuesto diferentes cartas de pago y haberle hecho firmar en blanco para engañarle en muchas cantidades en la administración de las rentas del mayorazgo de su marido, D. Rodrigo de Vargas Carrillo.

Ahora, y tras presentar esos poco edificantes hechos de su vida pasada, se relatan otros cargos. Por ejemplo, la amenaza; en 1658, intimidó, junto a otro escribano y a un alguacil, a un vecino que era aceitero, acusándole de comerciar fraudulentamente, y pidieron a la mujer del pobre hombre que les diese varios reales para componer la causa.

También, otros delitos tipificados como propios del oficio de escribano: por ejemplo, la falsificación documental, sobre lo que se le imputan cuatro cargos

\footnotetext{
58 Sobre el grupo de presión o facción, familiar y extrafamiliar, que le sirvió de cobertura al citado escribano, vid. supra.

59 ARChG, Legajo 107, pieza 7.

Hispania, LXV/2, núm. 220 (2005) 465-484
} 
distintos. Por uno de ellos se le acusa de la fabricación de una escritura por la que un tintorero recibía de una señora 200 ducados, a los que se obligaba a devolver; se presentó él a cobrarlos, diciendo que «estaba malo en la cama y que no podía venir por ellos», todo ello sin que el desafortunado tintorero tuviera noticia; al cumplirse el plazo de vencimiento de la obligación, y no haber devuelto los ducados a la señora, el tintorero fue preso.

Por último, en todas sus notas y registros entre los años 1655-1662, omitió poner los derechos que llevó a las partes por su otorgamiento; tampoco anotó el tipo de papel sellado en que había dado traslado de algunas escrituras, y, no podía faltar, llevó derechos excesivos. Asimismo, en ninguna de las causas y procesos que pasaron ante él durante nueve años, figuraron los derechos que debía llevar. A lo que podemos añadir algunas irregularidades con ciertos testigos: recibe sólo a un testigo cuando se necesitan dos, otros que no han firmado sus declaraciones, etc.

Para terminar, los excesos cometidos por Agustín Ignacio Salgado, vecino y escribano en Écija en la segunda mitad del Setecientos ${ }^{60}$.

Todas las pesquisas e indagaciones sobre su conducta, comienzan porque no se halla en su escribanía un protocolo sobre la institución de un mayorazgo que, supuestamente, pasó ante él tan sólo un año antes; a partir de aquí, se inicia un proceso de investigación. Como en tantas otras ocasiones, un acto delictivo, lleva al descubrimiento de otros cometidos por el mismo sujeto. Salgado, en su defensa, afirmó que no se castigó a otro escribano que había perdido cinco registros de su oficio, y que él era desgraciado por habérsele perdido una sola hoja.

Registrándose su despacho, también se descubre que en el oficio de Salgado se encontraron más de 50 piezas de autos criminales y civiles, unos con las falta de firmas del juez y del escribano y otros con falta de la de alguna de los dos, de modo que según se reconoce todo su oficio se halla trastornado. Y por si todo esto fuera poco, se le acusa de llevarse a su poder los bienes embargados como depósitos judiciales para su propio disfrute.

El escribano llega a decir que todo se trata de una conspiración que se ha tramado contra él, atreviéndose incluso a acusar directamente a los propios jueces de corruptos para no hacerle justicia. Según la acusación, con esta actitud el escribano Salgado intentaba «ver si consigue embrollarlo todo para no sufrir el castigo que le amenaza»; añade, que si se examinase a fondo su vida particular y ejercicio profesional, sería todo un cúmulo de enredos. Y concluye, de forma significativa, que "para los procedimientos dirigidos contra este escribano y providencias que contra él se han dado, bastaba mucho menos de lo que instrumentalmente se justifica, pero todo junto acredita ser uno de los peores que hay en la península».

60 ARChG, Legajo 4431, pieza 56. 
Puede que no fuera uno de los peores, pero, como hemos podido comprobar a lo largo de estas páginas, de seguro no fue el único en utilizar su oficio público en beneficio y provecho de sus propios intereses privados.

\section{CONCLUSIONES}

Lo visto hasta aquí, nos ha servido para comprobar la continua presencia que tuvieron las prácticas privadas y particulares, muchas ilícitas, en la función pública. Si bien, la confusión entre lo público y lo privado en el Antiguo Régimen no es ninguna novedad para nadie, en lo que no se ha incidido tanto es en cómo afecta esta relación a la imagen que tiene la sociedad de un colectivo profesional en concreto, así como en su propia identidad como tal colectivo.

Como se dijo al principio, tanto la historia institucional como la historia social tradicional, parecen ofrecer soluciones romas y carentes de perspectiva. A mi entender, sería provechoso e incluso necesario aunar una historia social basada en la familia y en los individuos, con una historia cultural de lo social a la manera de la que propugnó Roger Chartier hace ya algunos años.

Dicho lo cual, el panorama resultante podría ser muy parecido al que sigue. Por una parte, el imaginario social que se tuvo de unas pocas familias, consideradas paradigmáticas, se elevó a la categoría de identidad de todo el colectivo -lo que debe ser, que muchas veces no es-. Efectivamente, aquí, en el nivel más básico de la organización social, la familia, pudo iniciarse un proceso que, junto con aspectos socio-culturales, dotó de identidad a los escribanos públicos. Y todo ello sin olvidar, como hemos visto anteriormente, cómo la propia familia fue en ocasiones cómplice y encubridora de los delitos de los escribanos, especialmente en el medio rural, en donde podría decirse que no son tanto un colectivo profesional definido, sino que se diluyen y están socialmente identificados con los «poderosos» del lugar.

De igual forma, el imaginario social que se tiene de unas prácticas delictivas, se eleva a rango definitorio del colectivo - lo que no debe ser, que muchas veces es-; si en el discurso oficial, la profesión notarial es honrada y muy estimada, en el discurso de los que no pertenecen a la profesión, los escribanos son vistos como ejemplares amigos de lo ajeno. Esta percepción sin duda se vio influenciada por factores tales como el fulgurante ascenso de algunas familias, a pesar de su baja extracción social, y, no menos importante, por el desempeño de administraciones de rentas y patrimonios pertenecientes a las capas altas; fueron ellos los que ejercieron de acreedores, en permanente y directo contacto con los sectores populares que hacían las veces de arrendatarios. En la Edad Moderna, parece que es este segundo discurso, muy distinto al oficialista, el que se hace más fuerte, impregnando a todo el grupo profesional.

Precisamente, para evitar esto y para que se viese que no todos los escribanos eran semejantes y que no todos carecían de honra, acometieron la labor de

Hispania, LXV/2, núm. 220 (2005) 465-484 
(re)afirmarse ahondando las diferencias entre familias mediante prácticas basadas en la endogamia y la consecuente creación de «dinastías notariales» - lo que vengo definiendo como unas pocas familias paradigmáticas -, o quizás sea más apropiado hablar de «dinastías de notabilidad» formadas por escribanos, mercaderes, jurados y familiares del Santo Oficio; verdaderamente, son las mismas familias las que cuentan entre sus filas con unos y otros, y, en ocasiones, más de una de estas funciones se acumula en el mismo individuo. Aunque, si bien es verdad que el sustrato social del que proceden, no es determinante en cuanto a las prácticas desarrolladas por los mismos, ya se trate de prácticas endogámicas o de prácticas delictivas, sí que establece sus condiciones de posibilidad. Esto es, todos los escribanos «son» en potencia, o lo que es lo mismo, siempre tienen la posibilidad de ser pensados-así, de una forma u otra.

Por lo tanto, la percepción o imagen social de los escribanos públicos en el Antiguo Régimen pudo nutrirse de esta doble realidad, o mejor dicho, de esos dos niveles pertenecientes a una misma realidad: unas familias prototípicas, no muy numerosas, que desempeñan la profesión con ejemplaridad y se convierten en modelos referenciales, y unas prácticas delictivas que manchan y afectan a todo el colectivo en su enorme heterogeneidad. 